Journal of Molecular Structure, 48 (1978) 25-32

oElsevier Scientific Publishing Company, Amsterdam - Printed in The Netherlands

\title{
THE MICROWAVE SPECTRUM AND STRUCTURE OF TRIMETHYLAMINE-MONOFLUOROBORANE
}

\author{
PATRICK CASSOUX \\ Laboratoire de Chimie de Coordination, du CNRS, B.P. 4142, 31030 Toulouse-Cedex \\ (France) \\ ROBERT L. KUCZKOWSKI and GERALD D. FONG \\ Department of Chemistry, University of Michigan, Ann Arbor, Michigan 48109 (U.S.A.) \\ RUSSELL A. GEANANGEL \\ Department of Chemistry, University of Houston, Houston, Texas 77004 (U.S.A.)
}

(Received 21 October 1977)

\begin{abstract}
The microwave spectra of the ${ }^{11} \mathrm{~B}^{14} \mathrm{~N},{ }^{11} \mathrm{~B}^{15} \mathrm{~N},{ }^{10} \mathrm{~B}^{14} \mathrm{~N}$ and ${ }^{10} \mathrm{~B}^{15} \mathrm{~N}$ species of trimethylamine-monofluoroborane have been assigned in order to evaluate the $B-N$ distance. Analysis of the rotational constants using either the single or double substitution methods did not give highly precise results. However, by assuming parameters for the amine moiety found in other complexes and fitting the moments of inertia a value of $1.63 \pm 0.01 \AA$ was estimated. The method of predicate observables, an alternative fitting process, resulted in $d(B N)=1.633 \pm 0.006 \mathrm{~A}$ along with estimates for the other structural parameters.
\end{abstract}

\section{INTRODUCTION}

Several of the coordination compounds between $\mathrm{BX}_{3}$ and $\mathrm{NY}_{3}$ have been studied by microwave spectroscopy [1-4]. Only symmetric top species have been investigated and in some cases the $\mathrm{B}-\mathrm{N}$ distance has been obtained from spectra of the ${ }^{10} \mathrm{~B},{ }^{11} \mathrm{~B},{ }^{14} \mathrm{~N}$ or ${ }^{15} \mathrm{~N}$ species which occur in natural abundance or are readily enriched. This procedure makes use of Kraitchman's equations [5] (single substitution) or Pierce's method [6] (double substitution) when an atom has a small coordinate. These substitution techniques are attractive since good precision is usually obtained and the dative bond distance can be extracted with a minimum of isotopic work and assumptions.

Since there is a class of interesting coordination compounds which are asymmetric tops (for example, complexes between $\mathrm{Me}_{3} \mathrm{~N}$ and $\mathrm{BH}_{2} \mathrm{~F}, \mathrm{BHF}_{2}$ or $\mathrm{BH}_{2} \mathrm{CN}$ ), it seemed worthwhile to ascertain if a fairly precise $\mathrm{B}-\mathrm{N}$ distance could also be obtained for them from the spectra of the necessary isotopic species. In many of these examples at least one of the $\mathrm{B}$ or $\mathrm{N}$ coordinates are likely to be small and Pierce's method will have to be applied. This procedure has been outlined for asymmetric tops [7], although there have 
not been many applications [8-11]. $\mathrm{Me}_{3} \mathrm{NBH}_{2} \mathrm{~F}$ was an attractive choice to explore some of these aspects. One nitrogen coordinate was expected to be quite small but the necessary isotopes to apply the Pierce procedure could be readily synthesized from enriched samples of $\mathrm{Me}_{3} \mathrm{~N}-\mathrm{BH}_{3}$ used in an earlier microwave study. Also the detailed structures for $\mathrm{Me}_{3} \mathrm{NBH}_{3}$ [2] and $\mathrm{Me}_{3} \mathrm{NBF}_{3}$ [4] were available to help predict spectra and provide comparative data. Two reports of structures for $\mathrm{Me}_{3} \mathrm{NBH}_{3}$ determined by electron diffraction have recently appeared [12], which do not agree closely with the microwave determination [4].

\section{EXPERIMENTAL}

\section{Samples}

The samples were prepared by reacting $\mathrm{Me}_{3} \mathrm{NBH}_{3}$ with $\mathrm{HF}$ in benzene [13]. Purity was checked by PMR. The spectrum of $\mathrm{Me}_{3}{ }^{14} \mathrm{~N}^{11} \mathrm{BH}_{2} \mathrm{~F}$ was obtained from a sample containing the normal isotopic abundances. $\mathrm{Me}_{3}{ }^{14} \mathrm{~N}^{10} \mathrm{BH}_{2} \mathrm{~F}\left(93 \%{ }^{10} \mathrm{~B}\right), \mathrm{Me}_{3}{ }^{15} \mathrm{~N}^{10} \mathrm{BH}_{2} \mathrm{~F}\left(99 \%{ }^{15} \mathrm{~N}, 90 \%{ }^{10} \mathrm{~B}\right)$ and $\mathrm{Me}_{3}-$ ${ }^{15} \mathrm{~N}^{11} \mathrm{BH}_{2} \mathrm{~F}\left(95 \%{ }^{15} \mathrm{~N}, 80 \%{ }^{11} \mathrm{~B}\right)$ were also synthesized and spectra assigned. The enriched ${ }^{10} \mathrm{~B}$ species were obtained from enriched $\mathrm{Me}_{3} \mathrm{NBH}_{3}$ samples described previously [4]. $\mathrm{Me}_{3}{ }^{15} \mathrm{~N}$ was obtained by the reaction of ${ }^{15} \mathrm{NH}_{4} \mathrm{Cl}$ and $\left(\mathrm{CH}_{2} \mathrm{O}\right)_{n}$ [4].

\section{Spectrometers}

Spectra were obtained with a conventional Stark spectrometer with klystron sources. In the later stages of the work a Hewlett-Packard 8460A spectrometer was also used [14]. RF-MW double resonance was used to identify some transitions [15]. Frequencies were measured to $\pm 0.1 \mathrm{MHz}$. Spectra were measured at room temperature and vapor pressures between 0.02 and $0.06 \mathrm{~mm} \mathrm{Hg}$ were employed.

\section{Spectra}

The spectra were characterized by weak $\mu_{\mathrm{a}}$ and $\mu_{\mathrm{b}}$ transitions and assignments are listed in Tables 1 and 2 . The $\mu_{a}, R$-branch regions of a near proiate top were readily recognized. The classic pattern was observed: the $K=1$ transitions with characteristic Stark effects were well resolved from the center region where the closely spaced transitions from the other $K$ states occurred. In some cases the $K=0$ and a $K=2$ transition could be measured although not as conveniently due to neighboring lines and overlapping Stark lobes. From these $\mu_{\mathrm{a}}$ transitions, $B$ and $C$ could be determined with precision; however, the $A$ constant had a large uncertainty. Considerable effort was needed to assign the $\mu_{b}$ R-branch transitions and it was undertaken only for the ${ }^{14} \mathrm{~N}^{11} B$ species. Stark and RF-MW double resonance modulation techniques were employed. The RFDR experiment consisted of pumping the $6_{24} \rightarrow 6_{25} \mu_{\mathrm{a}}$ transition at $13.42 \mathrm{MHz}$. Under such conditions, the $5_{14} \rightarrow 6_{25}, 5_{15} \rightarrow 6_{24}$ and $6_{25} \rightarrow 7_{16}$ transitions could be observed. This 
TABLE 1

Transitions $(\mathrm{MHz})$ and rotational sonstants $(\mathrm{MHz})$ for $\mathrm{Me}_{3}{ }^{14} \mathrm{~N}^{11} \mathrm{BH}_{2} \mathrm{~F}$

\begin{tabular}{|c|c|c|c|c|c|}
\hline$\mu_{\mathrm{a}}-$ Trans. & $\nu$ (obs) & $\Delta \nu^{a}$ & $\mu_{L}$-Trans. & $v($ obs $)$ & $\Delta \nu$ \\
\hline $3_{13}-4_{14}$ & 20543.85 & 0.15 & $4_{06}$ & 27614.41 & 0.18 \\
\hline $4+3$ & 20635.59 & 0.22 & & 31764.Ẫ & $\overline{\mathbf{0}} . \overline{\mathbf{I}} \overline{0}$ \\
\hline & 25733.76 & 0.20 & & 36854.35 & -0.06 \\
\hline & 25679.42 & 0.15 & & 28997.26 & -0.23 \\
\hline & 25794.05 & 0.20 & & 37211.80 & 0.17 \\
\hline $5_{05}-606$ & 30878.21 & 0.05 & & 37766.57 & -0.23 \\
\hline $515-616$ & 30814.63 & 0.08 & $615-707$ & 34204.70 & -0.19 \\
\hline $5_{14}-6_{15}$ & 30952.15 & 0.08 & $6_{25}-7_{16}$ & 30207.40 & -0.25 \\
\hline $5_{23}-6_{24}$ & 30890.50 & -0.24 & & $22518.60^{c}$ & 0.18 \\
\hline $6_{06}-7_{07}$ & 36021.62 & -0.01 & $6_{52}-6_{61}$ & 22518.60 & 0.18 \\
\hline $6_{16}-7_{17}$ & $\mathbf{3 5 9 4 9 . 5 8}$ & -0.10 & $\begin{array}{l}6_{62}-771 \\
6_{61}-7_{70}\end{array}$ & $\begin{array}{l}26612.50^{c} \\
26612.50\end{array}$ & $\begin{array}{l}-0.20 \\
-0.20\end{array}$ \\
\hline \multicolumn{2}{|c|}{$A=4620.91 \pm 0.02^{b}$} & \multicolumn{2}{|c|}{$B=2585.20 \pm 0.01$} & \multicolumn{2}{|c|}{$C=2562.28 \pm 0.01$} \\
\hline
\end{tabular}

${ }^{a} \Delta \nu=\nu$ (obs.) $-\nu$ (calc. $) .{ }^{b}$ Uncertainties are twice the standard deviation from the frequency fit. ${ }^{c} \mathrm{Q}$-branch band heads.

TABLE 2

Observed $K=1$ asymmetry doublets, Q-branch band heads and rotational constants in $\mathbf{M H z}$

\begin{tabular}{llll}
\hline Transition & $\mathrm{Me}_{3}{ }^{15} \mathrm{~N}^{11} \mathrm{BH}_{2} \mathrm{~F}$ & $\mathrm{Me}_{3}{ }^{14} \mathrm{~N}^{10} \mathrm{BH}_{2} \mathrm{~F}$ & $\mathrm{Me}_{3}{ }^{15} \mathrm{~N}^{10} \mathrm{BH}_{2} \mathrm{~F}$ \\
\hline $3_{13}-4_{14}$ & $20520.59(0.18)^{\mathrm{a}}$ & $20692.55(0.15)$ & $20669.78(0.15)$ \\
$3_{12}-4_{13}$ & $20611.92(0.05)$ & $20741.66(0.04)$ & $20719.19(0.35)$ \\
$4_{14}-5_{15}$ & $25650.31(0.15)$ & $25865.50(0.10)$ & $25837.13(0.20)$ \\
$4_{13}-5_{14}$ & $25764.62(0.14)$ & $25927.11(0.19)$ & $25898.55(0.10)$ \\
$5_{15}-6_{16}$ & $30779.71(0.02)$ & $31038.40(0.07)$ & $31004.05(-0.12)$ \\
$5_{14}-6_{15}$ & $30916.83(0.20)$ & $31112.08(-0.07)$ & $31077.90(-0.08)$ \\
$6_{16}-7_{17}$ & $35908.72(-0.22)$ & $36210.98(-0.21)$ & $36171.20(-0.13)$ \\
$6_{15}-7_{16}$ & $36068.74(-0.14)$ & $36297.20(-0.10)$ & $36257.23(-0.20)$ \\
$6_{51}-6_{60}$ & $22554.10(-0.16)$ & $22729.30(0.00)$ & $22762.00(0.27)$ \\
$6_{52}-6_{61}$ & $22554.10(-0.16)$ & $22729.30(0.00)$ & $22762.00(0.27)$ \\
$7_{62}-7_{71}$ & $26655.20(0.14)$ & $b$ & $26900.00(-0.23)$ \\
$7_{61}-7_{70}$ & $26655.20(0.14)$ & $b$ & $26900.00(-0.23)$ \\
$A(\mathrm{MHz})$ & $4621.24 \pm 0.10$ & $4655.95 \pm 0.10$ & $4656.05 \pm 0.10$ \\
$B(\mathrm{MHz})$ & $2582.25 \pm 0.01$ & $2595.79 \pm 0.01$ & $2592.95 \pm 0.02$ \\
$C(\mathrm{MHz})$ & $2559.38 \pm 0.01$ & $2583.49 \pm 0.01$ & $2580.64 \pm 0.02$ \\
\hline
\end{tabular}

${ }^{a}$ In parentheses: $\nu$ (obs.) $-\nu$ (calc.). ${ }^{b}$ Band head obscured by interfering transition. 'Uncertainties are twice the standard deviation except for $A$ which was obtained by estimating an error of $\pm 2 \mathrm{MHz}$ in the $\mathrm{Q}$-branch band head. 
then led to observation of 7 additional b-type transitions by Stark modulation and a precise value of $A$ for the most abundant isotopic species.

When the HP spectrometer became available later in the study, it became apparent that the $\mu_{b}$ Q-branch transitions had band heads at intervals of approximately $2 A-B-C=4200 \mathrm{MHz}$. By measuring several of these band heads for the ${ }^{14} \mathrm{~N}-{ }^{11} \mathrm{~B}$ species, the value of $A$ extracted was identical to that obtained from the previously identified $\mu_{B}-R$-branch transitions. This method of assigning the $Q$-branch heads was then used to obtain $A$ for the other three isotopic species.

\section{STRUCTURE ANALYSIS}

Kraitchman analysis

With the four isotopic species, there are four possible calculations of the boron and nitrogen coordinates using Kraitchman's equations. The results are listed in Table 3 . The rotational constants used in these calculations were obtained for all isotopic species by a frequency fit of the same sets of transitions. Since the nitrogen atom lies close to the $a$ principal axis, zero point effects make the determination of the $b_{\mathrm{N}}$ coordinate inaccurate. Also, while $a_{\mathrm{N}}$ and $a_{\mathrm{B}}$ must have opposite signs, the relative signs of $b_{\mathrm{N}}$ and $b_{\mathrm{B}}$ are more ambiguous. Hence an uncertainty of several per cent results from using Kraitchman's equations.

Second difference analysis

This breakdown in the substitution equation can be alleviated in principle by the second difference method [7]. The method requires four isotopic species with substitution in two different frameworks as in the present case: ${ }^{14} \mathrm{~N}-{ }^{11} \mathrm{~B},{ }^{15} \mathrm{~N}-{ }^{11} \mathrm{~B}$ and ${ }^{14} \mathrm{~N}-{ }^{10} \mathrm{~B},{ }^{15} \mathrm{~N}-{ }^{10} \mathrm{~B}$. Because values of $\Delta \Delta I_{\mathrm{a}}$ or $\Delta \Delta I_{\mathrm{c}}$ are available, either of the relationships derived by Krisher and Pierce [7] relating them to the small $b_{\mathrm{N}}$ coordinate can be used. However, it was found that the experimental uncertainties of about $\pm 0.007 \mathrm{u} \AA^{2}$ in $\Delta \Delta I_{\mathrm{a}}$ and \pm 0.003 in $\Delta \Delta I_{\mathrm{c}}$ were too large to yield reliable values for the coordinate. For example, TABLE 3

Boron and nitrogen coordinates ( $($ ) from Kraitchman substitution method

\begin{tabular}{|c|c|c|c|c|c|}
\hline Parent & $\left|a_{N}\right|$ & $\left|b_{N}\right|$ & $\left|a_{\mathrm{B}}\right|$ & $\left|b_{B}\right|$ & $d(B N)$ \\
\hline $\begin{array}{l}14_{N^{11}} 1_{B} \\
15_{N} 11_{B} \\
14_{N} 10_{B}\end{array}$ & $\begin{array}{l}0.480(2)^{\mathrm{a}} \\
0.475(2) \\
0.469(3)\end{array}$ & $\begin{array}{l}0^{b}(0.02) \\
0^{b}(0.02) \\
0.013(20)\end{array}$ & $\begin{array}{l}0.894(1) \\
0.900(1) \\
0.895(1)\end{array}$ & $\begin{array}{l}0.900(1) \\
0.897(1) \\
0.917(1)\end{array}$ & $\begin{array}{r}1.643(20) \\
1.642(20) \\
1.651(20) \\
\text { or } 1.636(20)\end{array}$ \\
\hline $15_{\mathrm{N}} 10$ & $0.463(3)$ & $0.015(20)$ & $0.901(1)$ & $0.916(1)$ & $\begin{array}{r}1.650(20) \\
\text { or } 1.636(20)\end{array}$ \\
\hline
\end{tabular}

a Uncertainties from experimental error except for $a_{\mathrm{N}}$ where $\pm 0.02 \AA$ was assumed. ${ }^{\mathrm{b}}$ Set at zero since an imaginary value was calculated. 
the $\Delta \Delta I_{\mathrm{c}}$ equation resulted in $b_{\mathrm{N}}=0.08 \pm 0.20 \AA$. It became obvious that rotational constants at least an order of magnitude more accurate would be needed which seems out of reach in this case.

It is worth noting that an inspection of some other reported applications of the double substitution procedure to asymmetric tops indicated that such ambiguities are not uncommon. This was the case for $\mathrm{HNO}_{3}$ [8], $\mathrm{CH}_{3} \mathrm{SiHF}_{2}[7]$ and ethylene ozonide $[9,10]$. Satisfactory applications include $\mathrm{CH}_{3} \mathrm{SiH}_{2} \mathrm{~F}$ [7] and CINCO [11]. Successful applications to linear and symmetric tops are also well documented $[4,6,16]$.

\section{Moment of inertia analysis}

Another method explored was to assume a set of structural parameters and then fit the observed moments to a small number of structural parameters including $d(\mathrm{BN})$. The program STRFITQ was used* [17]. In principle there are ten independent structural parameters for a symmetric $\mathrm{Me}_{3} \mathrm{~N}$ group and it might appear that a number of these could be determined since $12 I$ 's are available. However, not all are independent and linear dependences arise during the fitting process. It was found convenient to assume at least five of the structural parameters and fit the eight values of $I_{\mathrm{B}}$ and $I_{\mathrm{C}}$. Only values of $I_{\mathrm{B}}$ and $I_{\mathrm{C}}$ were used since this approach was explored before the reliable values of $I_{\mathrm{a}}$ were available. Values for $d(\mathrm{CH}), d(\mathrm{BH}), \angle N C H, \angle B N C$ and either $d(\mathrm{NC})$ or $d(\mathrm{BF})$ close to those in $\mathrm{Me}_{3} \mathrm{NBF}_{3}$ and $\mathrm{Me}_{3} \mathrm{NBH}_{3}$ were assumed. These assumptions were varied over a small range including a slight asymmetry in the $\mathrm{Me}_{3} \mathrm{~N}$ group. The assumptions and results are listed in Table 4. It is seen that the value of $d(\mathrm{BN})$ falls in the range of $1.63 \pm 0.01 \AA$ and is essentially fixed to the narrow range by the isotope shifts and assumptions involving the $\mathrm{Me}_{3} \mathrm{~N}$ group. The $d(\mathrm{CN})$ and $d(\mathrm{BF})$ distances are highly correlated and if a value for one is assumed close to the value in the $\mathrm{BH}_{3}$ or $\mathrm{BF}_{3}$ adducts, then the other parameter is from 0.025 to $0.04 \AA$ longer than in those adducts. It would appear that this method of structure fitting may be a suitable alternative to evaluation of the $B-N$ distance provided that an additional structural parameter involving the nitrogen atom such as $\angle \mathrm{BNC}$ or $d(\mathrm{NC})$ can be reasonably assumed in a narrow range.

\section{Method of predicate observables}

When the twelve moments of inertia became available, it was decided to fit this data to structural parameters using the method of predicate observables described by Bartell et al. [18]. This method efficiently fits by a least squares procedure the 12 moments of inertia along with the predicate observables listed in Table 5 weighted inversely proportional to the square of the respective uncertainties. These predicate observables and their

*STRFITQ is parameterized to work with internal structural parameters rather than Cartesian coordinates. In practice the $I$ 's themselves are not directly fit but the differences between experimental values and a model are minimized. 


\section{TABLE 4}

Structures which fit $I_{B}$ and $I_{C}$ for the four isotopic species

\begin{tabular}{|c|c|c|c|c|}
\hline Assumed ${ }^{a}$ & Detern & nined $^{\mathbf{b}}$ & & \\
\hline $\begin{array}{l}d(\mathrm{BH})=1.21 \pm 0.01 \\
d(\mathrm{CH})=1.095 \pm 0.015 \\
d(\mathrm{NC})=1.479 \pm 0.004 \\
\angle \mathrm{BNC}=110.0 \pm 0.3 \\
\angle \mathrm{NCH}=110.6 \pm 0.6\end{array}$ & $\begin{array}{l}a_{\mathrm{B}} \\
a_{\mathrm{N}} \\
d(\mathrm{BN}) \\
\angle \mathrm{NBF} \\
\angle \mathrm{NBH}\end{array}$ & $\begin{array}{l}=-0.8940(1) \\
=0.4755(3) \\
=1.632 \pm 0.006 \\
=105.8 \pm 2 \\
=100 \pm 25\end{array}$ & $\begin{array}{l}b_{\mathbf{B}} \\
b_{\mathbf{N}} \\
d(\mathrm{BF}) \\
\angle \mathrm{HBH}\end{array}$ & $\begin{array}{l}=-0.8987(1) \\
=-0.010(15) \\
=1.41 \pm 0.01 \\
=93 \pm 20\end{array}$ \\
\hline $\begin{aligned} & d(\mathrm{BH})=1.21 d(\mathrm{CH})=1.095 \\
& d\left(\mathrm{NC}_{1}\right)=1.475 \text { or } 1.483 \\
& d\left(\mathrm{NC}_{2}\right)=d\left(\mathrm{NC}_{3}\right)=1.483 \\
& \text { or } 1.475 \\
& \angle \mathrm{NCH}=110.6 \\
& \angle \mathrm{BNC}_{1}=109.8 \text { or } 110.4 \\
& \angle \mathrm{BNC}_{2}=\angle \mathrm{BNC}_{3}=110.4 \\
& \text { or } 109.8\end{aligned}$ & $\begin{array}{l}a_{\mathrm{B}} \\
a_{N} \\
d(\mathrm{BN}) \\
d(\mathrm{BF}) \\
\angle \mathrm{NBF} \\
\angle \mathrm{NBH} \\
\angle \mathrm{HBH}\end{array}$ & $\begin{array}{l}=-0.8940(1) \\
=0.4757(2) \\
=1.632 \pm 0.003 \\
=1.410 \pm 0.005 \\
=105.9 \pm 0.7 \\
=100 \pm 25 \\
=93 \pm 20\end{array}$ & $\begin{array}{l}b_{\mathbf{B}} \\
b_{\mathbf{N}}\end{array}$ & $\begin{array}{l}=-0.8986(1) \\
=-0.010(5)\end{array}$ \\
\hline $\begin{array}{l}d(\mathrm{BH})=1.21 \\
d(\mathrm{CH})=1.095 \\
d(\mathrm{BF})=1.387 \\
\angle \mathrm{BNC}=110.1 \\
\angle \mathrm{NCH}=110.6\end{array}$ & $\begin{array}{l}a_{\mathrm{B}} \\
a_{\mathrm{N}} \\
d(\mathrm{BN}) \\
\angle \mathrm{NBF} \\
\angle \mathrm{NBH}\end{array}$ & $\begin{array}{l}=-0.8942 \\
=0.4752 \\
=1.624 \\
=102.9 \\
=138\end{array}$ & $\begin{array}{l}b_{\mathrm{B}} \\
b_{\mathrm{N}} \\
d(\mathrm{CN}) \\
\angle \mathrm{HBH}\end{array}$ & $\begin{array}{l}=0.8986 \\
=-0.025 \\
=1.501 \\
=82\end{array}$ \\
\hline
\end{tabular}

aUnits are $\AA$ and degrees. ${ }^{b}$ Uncertainties determined by varying the assumptions over the stated ranges.

TABLE 5

Structure determined by predicate observables method

\begin{tabular}{lcc}
\hline & Predicate observable & Final value $^{\mathrm{a}}$ \\
\hline$d(\mathrm{CH})(\AA)$ & $1.095 \pm 0.02$ & $1.097 \pm 0.01$ \\
$d(\mathrm{BH})(\AA)$ & $1.21 \pm 0.02$ & $1.210 \pm 0.01$ \\
$d(\mathrm{BN})(\AA)$ & $1.637 \pm 0.02$ & $1.633 \pm 0.006$ \\
$d(\mathrm{BF})(\AA)$ & $1.370 \pm 0.05$ & $1.402 \pm 0.015$ \\
$d\left(\mathrm{C}_{1} \mathrm{~N}\right)(\AA)$ & $1.470 \pm 0.04$ & $1.492 \pm 0.009$ \\
$d\left(\mathrm{C}_{2} N\right)=d\left(\mathrm{C}_{3} \mathrm{~N}\right)(\AA)$ & $1.470 \pm 0.04$ & $1.494 \pm 0.016$ \\
$\angle \mathrm{NBH}$ & $105 \pm 7^{\circ}$ & $104.7 \pm 3.7^{\circ}$ \\
$\angle \mathrm{NBF}$ & $106 \pm 4^{\circ}$ & $105.3 \pm 0.5^{\circ}$ \\
$\angle \mathrm{C}_{1} \mathrm{NB}$ & $109 \pm 3^{\circ}$ & $109.5 \pm 1.0^{\circ}$ \\
$\angle \mathrm{C}_{2} \mathrm{NB}=\angle \mathrm{C}_{3} \mathrm{NB}$ & $109 \pm 3^{\circ}$ & $110.1 \pm 0.5^{\circ}$ \\
$\angle \mathrm{NCH}$ & $109 \pm 2^{\circ}$ & $109.2 \pm 1.0^{\circ}$ \\
$\tau(\mathrm{HBNF})$ & $120 \pm 7^{\circ}$ & $120 \pm 2.7^{\circ}$ \\
$\tau\left(\mathrm{C}_{2} \mathrm{NBF}\right)$ & $60 \pm 7^{\circ}$ & $60.0 \pm 0.7^{\circ}$ \\
\hline
\end{tabular}

${ }^{a}$ This structure gave the following coordinates for the ${ }^{14} N^{1} B$ species: $a_{N}=0.476$;

$b_{\mathrm{N}}=-0.010 ; a_{\mathrm{B}}=-0.894 ; b_{\mathrm{B}}=-0.898$. 
variances are estimated by inspecting data from analogous molecules and essentially introduce into the fitting process, the likely range for that quantity. However, the relative weighting of true observables (or $I$ 's) and the predicate observables was chosen so that the final fit would give good agreement with the observed $I$ 's but not necessarily constrain a structural parameter to a value within the predicate observable's range of variance. The advantage of this fitting process is that it determines a set of parameters consistent with experimental data and experience along with an estimated plausible range for these parameters via the error matrix. It does this more efficiently than the tedious process described in the previous section where many calculations for various rigid structural assumptions must be made.

The final result of this fitting process is listed in Table 5. These structural values (when unrounded) fit all the observed moments to within $\pm 0.004 u \AA^{2}$ and gave coordinates for $a_{N}, a_{B}$ and $b_{B}$ within $\pm 0.004 \AA$ for the four parent species listed in Table 3. Some qualification is necessary in interpreting these results. The final values listed can be interpreted as structural parameters which fit the $I$ 's closely but not necessarily uniquely. Alternatively, the final values with their attached variances can be described as the most likely range for that parameter given the experimental data and parameter values from similar species*.

The method of predicate observables provides strong support that $d(\mathrm{BN})$ is $1.633 \pm 0.006 \AA$ and is close to the values in $\mathrm{Me}_{3} \mathrm{NBF}_{3}(1.636 \pm 0.004$ [2]) and $\mathrm{Me}_{3} \mathrm{NBH}_{3}(1.638 \pm 0.01 \AA$ [4]). All the bond angles are also likely to be within $1-2^{\circ}$ of the analogous parameters in these adducts (except possibly $\angle N B H$ which is not well determined). The mid-range values of $d(C N)$ and $d(B F)$ in Table 5 are all slightly longer $(\sim 0.01-0.02 \AA)$ than in the symmetric adducts (cf. assumptions in Table 4) although the variances overlap for these parameters. The CN and BF bond distances are highly correlated in the available moments of inertia and it is likely that if $d(\mathrm{CN})$ is close to the value in the other two adducts then $d(\mathrm{BF})$ must lengthen to about $1.41-1.42 \AA$. Conversely if $\alpha(B F)$ is near the value $1.387 \AA$ in the $\mathrm{BF}_{3}$ adduct then $d(\mathrm{CN})$ will lengthen to about $1.50 \AA$.

In summary, all the available data indicate strongly that $d(\mathrm{BN})$ is close to the value in the $\mathrm{BH}_{3}$ and $\mathrm{BF}_{3}$ adducts but that there is some possibly interesting deviance in either $d(\mathrm{CN})$ or $d(\mathrm{BF})$ (or for both parameters) from those adducts. The available experimental data is insufficient to permit a distinct choice between these interesting alternatives.

\footnotetext{
*An element of judgment enters into the choice of "likely range" since the parameter values and their deviances can change if a different set of predicate observables, their variances or weighting schemes are chosen. For example, in another calculation, the predicate observables in Table 5 were used except that larger uncercainty ranges in the three heavy atom bond distances $(A)$ were chosen : $d(C N)=1.47 \pm 0.14, d(B F)=1.37$ $\pm 0.14, d(B N)=1.637 \pm 0.07$. This gave essentially the same final structure and variances except for the following parameters: $d\left(\mathrm{C}_{2} \mathrm{~N}\right)=d\left(\mathrm{C}_{3} \mathrm{~N}\right)=1.502 \pm 0.033, d(\mathrm{BF})=1.396$ \pm 0.027 and $d(B N)=1.634 \pm 0.010$.
} 


\section{ACKNOWLEDGEMENTS}

The authors are grateful to the NATO Scientific Affairs Division for the support of this work (Research Grant No. 925). The work was also supported by grants from the National Science Foundation (GP 38750X1 and CHE 76-09572) and from the Robert A. Welch Foundation (E-439). We are grateful to Professor L. S. Bartell for the use of the Predicate Observable Computer program and to Dr. R. Creswell and Professor R. Schwendeman of Michigan State University for help in initially conducting the RF-MW experiments. The helpful assistance of J. Aussoliel is acknowledged.

\section{REFERENCES}

1 D. R. Lide, Jr., R. W. Taft, Jr. and P. Love, J. Chem. Phys., 31 (1959) 561.

2 P. S. Bryan and R. L. Kuczkowski, Inorg. Chem., 11 (1972) 553 ;P. Cassoux, R. L. Kuczkowski and A. Serafini, Inorg. Chem., 16 (1977) 3005.

3 J. R. Durig, Y. S. Li, L. A. Carreira and J. D. Odom, J. Am. Chem. Soc., 95 (1973) 2491.

4 P. Cassoux, R. L. Kuczkowski, P. S. Bryan and R. C. Taylor, Inorg. Chem., 14 (1975) 126.

5 J. Kraitchman, Am. J. Phys., 21 (1953) 17.

6 L. Pierce, J. Mol. Spectrosc., 3 (1969) 575.

7 L. C. Krisher and L. Pierce, J. Chem. Phys., 32 (1960) 1619.

8 A. P. Cox and J. M. Riveros, J. Chem. Phys., 42 (1965) 3106.

9 R. L. Kuczkowski, C. W. Gillies and R. L. Gallaher, J. Mol. Spectrosc., 60 (1976) 361.

10 U. Mazur and R. L. Kuczkowski, J. Mol. Spectrose., 65 (1977) 84.

11 W. H. Hocking, M. L. Williams and M. C. L. Gerry, J. Mol. Spectrosc., 58 (1975) 250.

12 S. Shibata and K. Lijima, Chem. Lett., (1977) 20; M. Hargittai and I. Hargittai, J. Mol. Struct., 39 (1977) 79.

13 J. M. VanPaasschen and R. A. Geanangel, J. Am. Chem. Soc., 94 (1972) 2680.

14 D. R. Johnson and R. Pearson, Jr., Methods of Experimental Physics, Vol. 13, Spectroscopy, Part B, Academic Press, New York, 1976.

15 F. J. Wodarczyk and E. B. Wilson, J. Mol. Spectrosc., 37 (1971) 445.

16 A. C. Venkatachar, R. C. Taylor and R. L. Kuczkowski, J. Mol. Struct., 38 (1977) 17.

17 R. S. Schwendeman, Critical Evaluation of Chemical and Physical Structural Information, National Academy of Science, Washington, D.C., 1974.

is L. S. Bartell, D. Romanesko and T. C. Wong, Molecular Structure by Diffraction Techniques, Specialist Periodical Report, The Chemical Society, London, 1975, Vol. 3, Chap. 4. 